\title{
НОВАЯ СТРАТЕГИЯ БИЗНЕСА ГРУППЫ КОМПАНИЙ «ИЗОВАК»
}

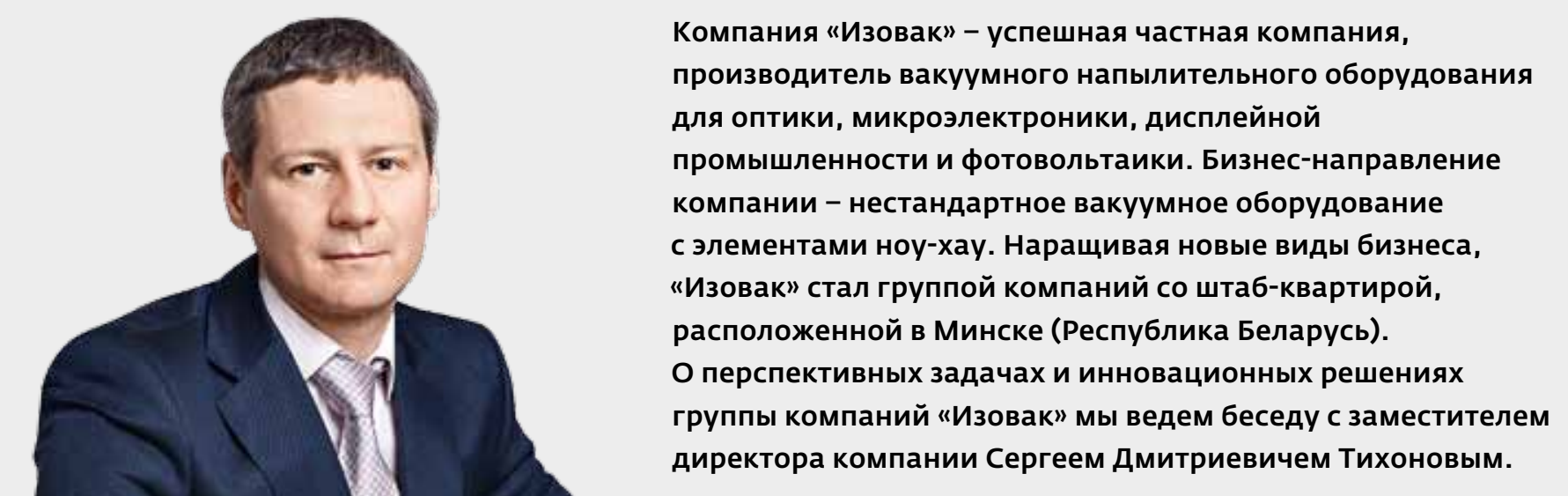

Сергей Дмитриевич, со времени нашего прошлого интервью прошло 8 лет. Основные тренды развития фотоники за это время не изменились, но на рынке появились новые игроки, неопределенности технологических рисков трансформировались в новые технические предпочтения. Коснулись ли эти изменения бизнеса компании "Изовак", одного из крупных участников рынка по производству вакуумного оборудования?

Группа компаний «Изовак" - компания международная. Основные направления компании "Изовак" не изменились: вакуумное оборудование для нанесения покрытий, оптические системы контроля нанесения многослойных покрытий и отдельные компоненты и сервис по нанесению покрытий. Наше оборудование является звеном в цепочке производства конечного изделия наших заказчиков.

Российским производителям "Изовак" известен как крупнейший в СНГ экспортер вакуумного оборудования и как крупнейший партнер таких мировых промышленных лидеров, как Apple, Sharp, LG, Samsung и др. В этом году мы уже отпраздновали 27 лет основания ком- пании. Согласитесь, 27 лет - это значительный срок, наработан огромный опыт.

Мы нашли надежных партнеров в России, Канаде, Китае. На азиатских рынках компания «Изовак" присутствует давно, более 20 лет. Азия - один из самых динамично развивающихся регионов. Промышленная политика там направлена на развитие малого и среднего бизнеса, и наше присутствие на Тайване позволяет нам динамично развиваться (70\% сенсорных панелей, изготовленных на азиатских заводах, выполнены на нашем оборудовании). А партнерское соглашение с канадской компанией IntlVac поддерживает присутствие "Изовак" на американском рынке и позволяет быстро реагировать на изменения в мировой индустрии фотоники.

Какие крупные проекты ведет «Изовак"?

Научно-техническая компания "Изовак" специализируется на разработке и оптимизации оптических покрытий, перспективных технологиях напыления тонких покрытий, изготовлении оптических компонентов, производстве технологических устройств и вакуумных уста- 
новок для нанесения тонкопленочных покрытий. В нашем портфолио более 300 успешно выполненных проектов по всему миру. Сегодня в нашем портфеле более 50 самых различных проектов, начиная от изготовления линейного оборудования для солнечной энергетики и дисплейного производства и заканчивая услугами по нанесению олеофобных покрытий на обтекатели вертолетных систем контроля.

Расскажите, пожалуйста, о структуре группы компаний "Изовак".

Мы приняли решение выводить некоторые свои новые разработки в старт-апы и в отдельные компании. Соответственно головная компания "Изовак", которая специализируется на разработке и производстве вакуумного напылительного оборудования, осталась основной. В ее отделах идут разработки больших комплексных проектов. Эти проекты предназначены под разработку не какого-то единичного оборудования, а направлены на создание цехов или лабораторий под ключ. Мы за счет своей компетенции и 27-летнего опыта не только поставляем вакуумное оборудование, но и создаем производственные и научные комплексы. Также компания ведет разработки компьютерных симуляций процессов, происходящих в плазме, моделирование магнитных, электрических и тепловых полей, возникающих в оборудовании. Для этих задач создан отдел системного конструирования.

Вторая компания, «Изовак. Технологии", специализируется на услугах по нанесению покрытий, в основном оптических, а также на разработках различных технологических устройств и на самой технологии нанесения тонких пленок.

Совсем недавно к группе компаний присоединилась компания "Изовак дР» (дополненная реальность). У нее два основных продукта: системы дополненной реальности и системы оптического контроля. Технология видеомодуля дополненной реальности - модная и развивающаяся тема. А там, где есть оптические покрытия, проявляется наша спе- циализация, потому что мы работали во всех этих сферах и имеем богатый опыт.

От имени этой компании мы вывели на рынок новый продукт и сейчас идем с ним на зарубежные рынки: на Запад и в США - это встроенная система автоматического оптического контроля ОСР (Optical Coating Provider) Broadband, которая заменяет технолога-разработчика на установке для нанесения сложных многослойных неравнотолщинных оптических покрытий.

Это основные компании.

Кроме того, у нас есть тайваньская компания-партнер ITC. Компания ITC специализируется на логистике и продвижении нашей продукции на всю Азию: Тайвань, Китай, Корею, Японию. Мы открыли новый сборочный цех. Планируем выйти на рынок континентального Китая, уже открылся китайский сайт компании "Изовак". Считаем также перспективным рынком Индию.

\section{Быстро реагировать на изменения в мировой индустрии фотоники}

Еще в составе группы есть компания "Соликс", которая специализируется на выращивании кристаллов - алексан ${ }^{-}$ дрит, титан-сапфир и ванадат. Такие кристаллы, как александрит, на мировой рынок лазерных кристаллов поставляют не более 5 компаний. Мы считаем это довольно перспективным направлением. Анализ рынка показал, что существующая конкуренция - небольшая, а кристаллы высокого качества делают только американцы и мы. Наши предположения подтвердились, и когда мы приняли участие в феврале этого года в американской выставке Photonics West, то от заказчиков не было отбоя.

Какими качествами обладает кристалл александрита? Почему к нему такое внимание?

Александрит (кристалл $\mathrm{BeAl}_{2} \mathrm{O}_{4}$ ) уникален тем, что на его основе можно делать перестраиваемые лазеры. Перестраива- 
емые лазеры - новый тип медицинских универсальных лазеров, которые подходят для различных типов операций. Их использование стало новой тенденцией в медицине. "Изовак" растит кристаллические були диаметром 60 мм и высотой 120-130 мм методом Чохральского, затем специалисты высверливают в них стержни диаметром 6 мм. Мы считаем, что это направление, во-первых, пер спективно, а, во-вторых, на этом поле у нас не так много конкурентов.

Давайте поговорим о конкурентной борьбе. Не секрет, что рост стонмости вакуумного оборудования для нанесения тонких пленок ведет к тому, что потребители, экономя на покупке дорогого оборудования, обращаются в сервисы по напылению. Есть вероят ность, что темпы продаж вакуумного оборудования будут снижаться?

Мы не ощутили снижения спроса на оборудование для нанесения вакуумных покрытий. По-прежнему основная продуктовая линейка компании “Изовак" это вакуумное напылительное оборудование для оптики, микроэлектроники, дисплейной промышленности и фотовольтаики. Мы владеем технологиями ионно-лучевого распыления, ионнолучевой очистки, ионно-лучевого ассистирования, магнетронного распыления, год назад освоили новые методы PECVD. Наша специализация - это вакуумная техника для любых применений, но бизнес-направление компании - это нестандартное вакуумное оборудование с элементами ноу-хау.

\section{Сердие оптического вакуумного оборудования - это система контроля ОСР Broadband}

На рынке нанесения покрытий постоянно наблюдается спрос на новые инновационные продукты. В связи с потребностью в нанесении покрытий для лазерной оптики, обладающих высокой лучевой прочностью, мы выпустили новый продукт - LIDIZ. LIDIZ - это вакуумная напылительная установка техно- логической линии вертикального типа для покрытий с низким рассеиванием и высокой лучевой стойкостью для лазерных зеркал, фильтров и элементов с просветляющими покрытиями. В установке реализована технология осаждения материала высокочастотным ионно-лучевым распылением. В ней используется наш новый разработанный ионный источник, разработанный специально для решения задач нанесения прецизионных многослойных покрытий с высокой плотностью и низкой шероховатостью. Загрузка и выгрузка подложкодержателя в LIDIZ для защиты от загрязнений идет через шлюзовую камеру. Подложкодержатель имеет диаметр 320 мм, равномерность покрытий в зоне подложкодержателя составляет от 200 мм до 285 мм с отклонением $\pm 0,5 \%$. Эффективная площадь нанесения с учетом свидетелей

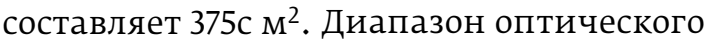
контроля 350-1650нм, разрешающая способность 0,5 нм.

Ныне наблюдается всплеск предложений на рынке вакуумного оборудования. Как компания отреагировала на эти изменения, пришлось ли что-то менять в инновационной политике компании?

Есть разные методы борьбы с $\mathrm{KoH}^{-}$ курентами: можно бороться с ними, а можно постоянно улучшать свой продукт. Для уверенного развития бизнеса необходимо открывать новые направления, наращивать присутствие на других региональных и отраслевых рынках. Мы постоянно обновляем линейку продуктов и сервисов, которые находят применение во многих отраслях промышленности. Как только активность в каком-то направлении снижается, интенсивность продаж нарастает в другом направлении. Применение более современных вакуумных покрытий является фактором экономики, а не повышением затрат. Кто не владеет технологиями нанесения покрытий, в конечном итоге понесет потери при реализации своего продукта.

Мы стали разрабатывать не только конечное оборудование, но и стали работать в сегменте В2В. Наши изделия 
позволяют заказчикам получать более конкурентоспособный продукт, который будет иметь высокие качественные и эксплуатационные характеристики.

Да, на рынке растет спрос на детали разного функционального назначения с тонкопленочными покрытиями. Оборудование для их нанесения выпускают многие компании. Однако вся сложность в нанесении тонкопленочных многослойных покрытий заключается не в умении рассчитать дизайн покрытия, буферные и адгезионные слои, а в возможностях проконтролировать их оптические характеристики. Сердце вакуумного оборудования - это система контроля ОСР Broadband и ПО.

Конструктор, разрабатывая дизайн покрытия, учитывает показатель преломления наносимого вещества и толщину пленки, а производитель ограничивает его возможности невысокой степенью воспроизводимости технологического процесса, которая связана с варьированием от партии к партии химического состава материала мишени распыления. Методы, основанные на контроле толщины слоя без учета оптических характеристик ранее нанесенных слоев, давно уже устарели. "Изовак" разработал встроенную оптическую систему контроля ОСР Broadband.

Комплекс оптического контроля OCP (Optical Coating Provider) Broadband учитывает оптические характеристики осаждаемых слоев и легко интегрируется в промышленное вакуумное оборудование различных видов в полностью автоматическом режиме в широком спектральном диапазоне с разрешением до 0,3 нм.

Принцип работы OCP Broadband прост: система может работать как по пропусканию, так и отражению. Дизайн, разработанный конструктором, задает старт работе программы контроля. Программа вычисляет спектр первого промежуточного слоя и ищет соответствующую ему толщину, анализируя постоянно меняющиеся оптические характеристики. В это время луч источника излучения через объектив направляется на свидетель, который расположен вместе с напыля- емыми подложками на неподвижном или вращающемся подложкодержателе. Затем луч, отражаясь от свидетеля и неся в себе информацию о параметрах спектра, попадает в спектроанализатор.

\section{Александрит уникален тем, что на его основе можно делать перестраиваемые пазеры}

Во время процесса напыления в зависимости от толщины и химического состава меняются оптические показатели покрытия. На дисплее мы наблюдаем постоянно меняющийся спектр слоев. Когда спектр оптимально совпадает с заданным рассчитанным рецептом, то программа определяет точку остановки для каждого слоя и дает команду на прекращение осаждения слоя и переход к процессу осаждения следующего слоя. Процесс повторяется, но уже с учетом характеристик предыдущего слоя. Если анализ показывает, что процесс осаждения не выходит на целевую оптическую характеристику, то для сохранения заданного спектра многокомпозиционого покрытия вступает в действие операция рециклинга или, другими словами, пересчета всего покрытия для получения требуемого результата. Она включает цикл пересчета спектра и оптимизации его толщины с учетом ранее осажденных на подложку слоев.

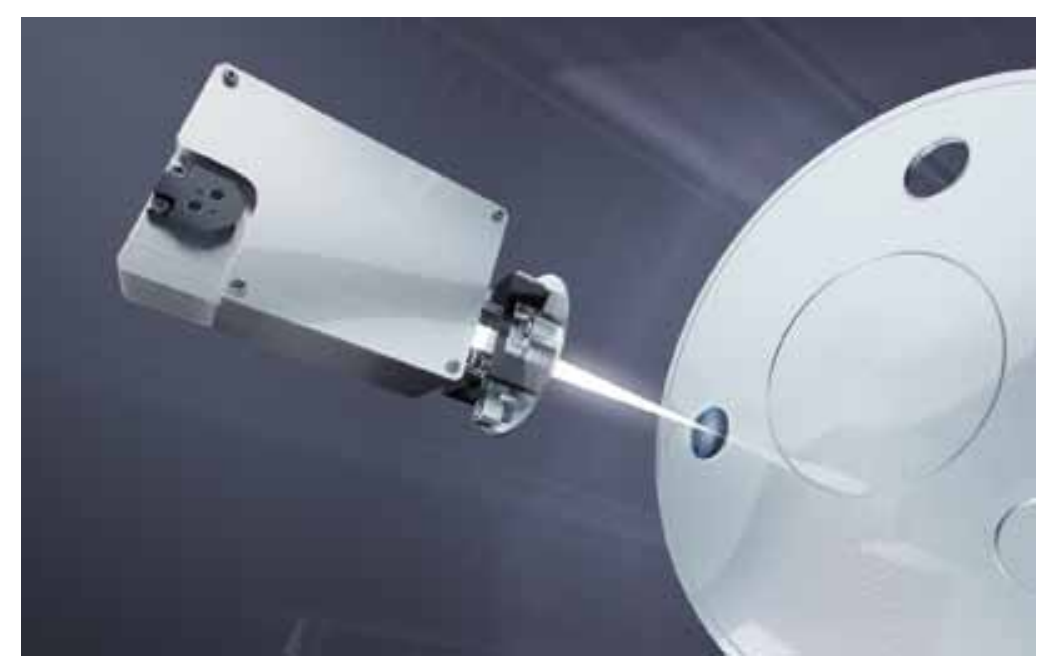




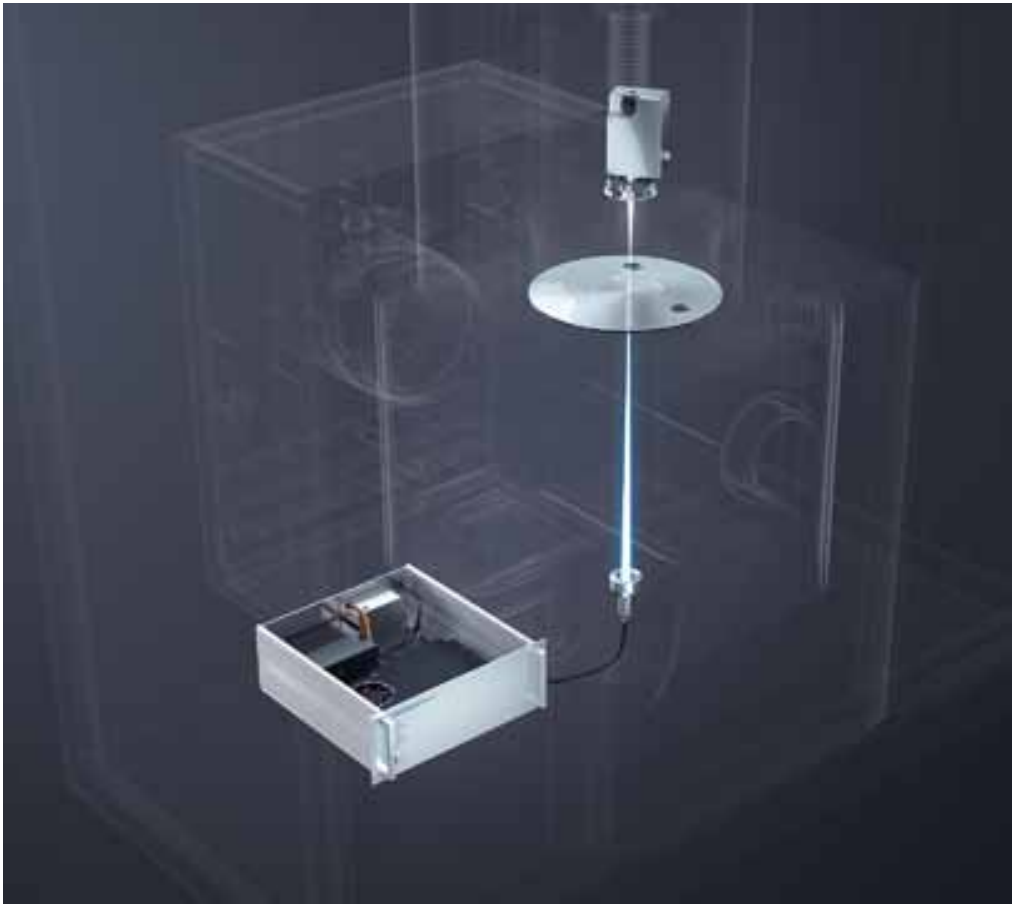

Таким образом, ОсР Broadband минимизирует выход браковочной продукции и исключает человеческий фактор.

Как вы боретесь с попытками скопировать ваше оборудование?

Мы стараемся защитить свои технологии и делаем мировые патенты (Япония, Америка, Китай), защищаясь на тех рынках, где идут продажи нашего оборудования. Эти работы ведет специальный отдел защиты интеллектуальной собственности и патентования "Изовак".

\section{Появляющиеся идеи быстро устаревают}

Однако надо понимать, что идеи возникают не только внутри компаний, но и за их пределами. Вместо зарабатывания денег на использовании своих технологий, надо получать деньги, используя различные выходы на рынки. Вместо управления своей интеллектуальной собственностью, надо получать прибыль от использования наших знаний соперниками. Хотя некоторые знания мы оставляем внутри компании, например технологию создания многозонных фильтров для дистанционной гиперспек- тральной съемки или нанесения алмазоподобных покрытий на Се-оптику.

Кроме того, не надо забывать, что появляющиеся идеи быстро устаревают. Именно по этой причине мы встали на путь создания старт-апов и отпочкования компаний, что связано с новой стратегией "Изовак": если технология не используется материнской компанией, то отпочкование побуждает технологию выходить на новые рынки. Это позволит разобраться с запросами новых потребителей и обнаружить новые возможности. Люди могут использовать технологию таким образом, о котором мы, ее разработчики, ранее не задумывались.

Не с этой ли стратегией бизнеса связано недавнее создание компании «ИЗОВАК ДР»?

Да, появление компании "Изовак ДР" связано с мировой тенденцией к формированию дополненной реальности (Augmented Reality - AR) для гражданских и военных применений. Разработки дисплеев со встроенными серебряными нитями уже реализованы в конкретных продуктах, создание гибких дисплеев уже приняло вид стандартной технологии. Однако возникла новая идея дополнить VR-виды реальными картинами (Augmented Reality - AR). Идея быстро овладела умами инженеров. Такие системы дополненной реальности (VR/AR) оказались востребованными в медицине, например при проецировании на тело оперируемого человека картины его кровеносных сосудов или при обучении пилотов. Эти системы расширяют возможности оператора более реалистично оценивать обстановку. Чтобы изображение не расплывалось, нужны дисплеи с большим числом пикселов и высокой яркостью.

Hо сердцем VR/AR систем является модуль передачи изображения в глаз. В зрительной системе человека максимальное разрешение получается только в фовеальной области - узкой части сетчатки глаза. Мы компетентны в области создания таких модулей, улавливающих даже легкий поворот головы наблюдателя. Поэтому «Изовак ДР» скон- 
центрировал внимание на создании таких модулей и будет предлагать его рынку VR/AR-систем в разных нишах. Например, вы пришли в Эрмитаж, взяли 3D-очки, в них есть определенные метки, и вам уже не нужен гид: ничего не мешает вам смотреть на картину, при этом выплывает дополнительная графическая информация.

Существует рынок архитектурного стекла с гидрофобным покрытием. На недавних прошедших выставках "Изовак" демонстрировал гидрофобные и олеофобные покрытия". Какие проекты в этом направлении ведет компания?

Принимая во внимание климатические условия России и популярность архитектурных решений, воплощенных в стекле, можно ожидать существенного роста рынка оборудования для производства самоочищающегося строительного и архитектурного назначения. Подразделение "Изовак Технология" занимается созданием оборудования для нанесения гидрофобных и олеофобных покрытий. Эти покрытия, реализующие «эффект лотоса", обладают повышенными водои грязеотталкивающими свойствами. Более ранние технологии предполагали нанесение материала на стекло технологией напыления спрея или вакуумного распыления. Однако при достаточной простоте реализации эти покрытия при активной эксплуатации быстро изнашиваются и через 2-3 месяца эксплуатации выходят из строя. При относительной доступности запуск сложного технического оборудования дорог.

Своя технология нанесения гидрофобных покрытий, GTIZ, обеспечивает прозрачность покрытия. Оптическая прозрачность получаемого монослоя в сочетании с прекрасной химической стойкостью, износостойкостью позволяют использовать технологию в производстве планшетов, фотовидеокамер, экранов Touchscreen, в автомобильной промышленности, производстве архитектурного стекла, легко очищаемых защитных стеклах фотовольтаических панелей, датчиках, работающих в мас- ляной среде. А отсутствие возможностей зацепиться на поверхности бактериям делает эту технологию идеальным методом при создании лабораторных чистых комнат и медицинских помещений. Нанесение гидрофобных и олеофоб-

\section{Дия уверенного развития бизнеса необходимо открывать новые направления}

ных покрытий - это только первый шаг. Особенность технологии заключается в переносе монослоя выбранного материала на различные виды подложек, при этом сферы применения расширяются в разы.

Каковы перспективные задачи ставит перед собой "Изовак»?

Основная задача компании - выход на новые продуктовые рынки. Для этого мы прорабатываем серьезные совместные проекты участия в создании единого продукта с нашими зарубежными партнерами в различных странах, а иногда даже с конкурентами, которые начинают продвигать наши изделия, подобных которым нет в их продуктовой линейке. Наиболее перспективными мы считаем рынки по производству оборудования для нанесения покрытий с высокой лучевой стойкостью для мощных лазеров, рынки систем контроля нанесения покрытий, VR/AR-yстройств, кристаллов александрита, олеофобных и гидрофобных покрытий.

Для этих задач мы создаем новые старт-апы, которые в дальнейшем должны отпочковаться от материнской компании и дать технологиям возможность выхода на новые рынки. В компанию пришли молодые бизнесменеджеры, и в ближайшее время мы настроены на наращивание новых видов бизнеса и на здоровую агрессивную политику.

Благодарим за интересную беседу.

С С.Д. Тихоновым беседавали

Н. Л.Истомина и Л.В Карякина 